\title{
Brics - Novo Banco de Desenvolvimento
}

\author{
PAUlo Nogueira BATISTA JR. ${ }^{I}$
}

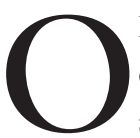

ECONOMISTa Paulo Nogueira Batista Jr., vice-presidente do Novo Banco de Desenvolvimento (NBD), estabelecido pelos Brics (sigla que se refere a Brasil, Rússia, Índia, China e África do Sul) na cidade chinesa de Xangai, respondeu por escrito no dia 10 de agosto as perguntas a seguir elaboradas pelo professor Rubens Rogério Sawaya (PUC-SP) a pedido da revista Estudos Avançados.

Estudos Avançados - Como surgiu a ideia da constituição do Novo Banco de Desenvolvimento (NBD) e qual foi o país que comandou o processo de criação?

A ideia partiu da Índia. Foi lançada na cúpula dos Brics (Brasil, Rússia, Índia, China e África do Sul) no início de 2012, em Nova Déli. Naquela ocasião, os líderes dos cinco países pediram a seus ministros de Finanças que examinassem a viabilidade de criar um novo banco de desenvolvimento para financiar infraestrutura e desenvolvimento sustentável. As negociações transcorreram por pouco mais de dois anos até a assinatura do Convênio Constitutivo na cúpula dos Brics em Fortaleza, em julho de 2014. Não se pode dizer que um país tenha comandado o processo de negociação. Os cinco participaram com igual presença e dedicação. Até o início de 2013, a Rússia ainda era mais relutante do que os outros, mas depois se engajou plenamente.

Estudos Avançados - Qual é o papel geopolítico do NBD ao ser constituído apenas por países emergentes? É um banco político? Como se insere na lógica geopolítica e de relação hegemônica global atual?

É primeira vez que um banco de desenvolvimento de alcance global é estabelecido apenas por países de economia emergente, sem a participação de países desenvolvidos na fase inicial. Trata-se, portanto, de um grande desafio para nós. A iniciativa de criar o NBD tem um aspecto geopolítico, sem dúvida. Reflete a insatisfação dos Brics com as instituições multilaterais existentes, que demoram a se adaptar ao século XXI e a dar suficiente poder decisório aos países em desenvolvimento. Mas o NBD não é um banco político. O banco se pautará por critérios técnicos para aprovar projetos. O nosso Convênio Constitutivo deixa esse ponto claro. Queremos evitar a excessiva politização das decisões que se observam nas instituições multilaterais existentes. 
Estudos Avançados - O NBD pretende se tornar um banco global?

Sim, o NBD está aberto a todos os países membros da ONU. Começamos a fazer contatos com outros países. A ideia é ter membros de todas as regiões do mundo - África, América Latina e Caribe, Ásia, Europa etc. Buscaremos trazer países desenvolvidos, de renda média e de menor nível de desenvolvimento. Mas só os países emergentes e em desenvolvimento poderão ser membros tomadores de empréstimos. Não faremos empréstimos a países desenvolvidos.

Estudos Avançados - Em que medida o NBD substitui ou complementa o Banco Mundial e outras instituições multilaterais da mesma espécie?

O NBD não substitui o Banco Mundial e outras instituições já estabelecidas. O nosso banco está apenas começando e só no médio e no longo prazos alcançará um volume expressivo de operações. O papel do NBD é complementar os esforços das instituições existentes no financiamento de projetos de infraestrutura e desenvolvimento sustentável. Estamos, inclusive, concluindo acordos de cooperação com outros bancos de desenvolvimento; alguns acordos já foram assinados. Mas, como diz o nome do nosso banco, a ideia é estabelecer uma entidade nova, levando em conta os erros e acertos dos bancos existentes. É fundamental para nós aprender com a experiência dos bancos mais antigos.

Sempre enfatizamos esse aspecto da cooperação/colaboração com as entidades mais antigas, um objetivo que estamos de fato começando a colocar em prática. Mas também é verdade que se as instituições multilaterais existentes, notadamente as sediadas em Washington, estivessem funcionando a contento, os Brics jamais teriam se dado ao trabalho de estabelecer o NBD, assim como um fundo monetário próprio, batizado de "Contingent Reserve Arrangement" (CRA). O tratado que criou o CRA também foi assinado na cúpula de Fortaleza.

Essas iniciativas dos Brics podem ser descritas como um "projeto anti-hegemônico", como observou Luiz Gonzaga Belluzzo. Elas fazem parte de um processo mais amplo: a "multipolarização" da arquitetura econômica e financeira mundial - uma diversificação do quadro institucional e das inciativas, com perda de peso relativo dos centros tradicionais de poder (FMI, Banco Mundial, OMC etc.). É um processo incipiente, mas já está em curso. Reflete em parte, como mencionei, a frustração dos países emergentes com a incapacidade do FMI e do Banco Mundial de se autorreformar em ritmo condizente com as transformações da economia mundial. Eu fui diretor executivo do FMI pelo Brasil e outros países por oito anos em Washington e conheço bem a resistência à mudança, a inércia institucional que caracteriza a governança das entidades de Bretton Woods. Houve algum progresso desde 2008, mas é ainda muito insuficiente.

Estudos Avançados - Quais as diferenças do NBD em relação aos bancos multilaterais existentes? 
Vou comparar o NBD com o outro banco multilateral de desenvolvimento que tem escopo global, o maior e mais importante deles - o Banco Mundial. Por exemplo, o Banco Mundial tem uma gama muito ampla e diversificada de atividades - é um banco de tipo "universal". Faz de tudo: financia, presta assistência técnica, estabelece condicionalidades, procura orientar as estratégias e políticas econômicas e setoriais dos países, estuda a economia mundial e as economias nacionais, dá consultoria, pretende ser uma fonte de conhecimento (um "knowledge bank"), organiza eventos, publica estudos e documentos, e assim por diante. O NBD pretende atuar de forma focada, não só nos anos iniciais, mas se depender de mim também depois, quando formos maiores. Seremos um banco de projetos na área de infraestrutura e desenvolvimento sustentável. E pretendemos concentrar esforços na área de infraestrutura sustentável, em setores como energia renovável (solar e eólica, por exemplo), eficiência energética, tratamento de esgotos, gestão sustentável de água, entre outros.

Outra diferença: o Banco Mundial tem uma estrutura pesada, procedimentos burocratizados e acaba demorando a aprovar projetos. O NBD pretende atuar com rapidez, sem sacrificar qualidade. O nosso objetivo é levar cerca de seis meses entre a identificação da maioria dos projetos e a aprovação na Diretoria. Já conseguimos isso na maioria dos projetos iniciais. A velocidade foi uma marca no primeiro ano do banco. Talvez seja a primeira vez na história que um banco multilateral de desenvolvimento conseguiu, já no seu primeiro ano, aprovar projetos e emitir seu primeiro bônus no mercado.

Estudos Avançados - Qual a visão de desenvolvimento do NBD e como essa visão se materializa em suas operações?

Seria pretensioso dizer que temos uma "visão de desenvolvimento" já elaborada. Creio que iremos desenvolver essa visão à medida que construirmos o banco, com base na experiência prática. Temos alguns pilares para nossa atuação, estabelecidos no próprio Convênio Constitutivo do NBD. Por exemplo, o NBD é um dos poucos - talvez seja o único - banco multilateral de desenvolvimento que tem a questão ambiental inscrita com destaque no próprio acordo ou convênio constitutivo. É um banco verde, desde a sua concepção. Para nós, a questão ambiental não é uma restrição, mas uma oportunidade e um foco central da instituição.

Outro aspecto importante: o NBD é um banco de países em desenvolvimento para países em desenvolvimento. Isso certamente condicionará a nossa visão. Pelo Convênio Constitutivo, a participação dos países de economia emergente e em desenvolvimento será sempre de pelo menos $80 \%$ do capital e do poder de voto. Os países avançados ou desenvolvidos poderão ingressar no banco, mas terão sua participação limitada a $20 \%$.

Estudos Avançados - Há algum papel especial da China ou preponderante nessa visão de desenvolvimento? 
Não. A sede do banco é na China, que tem a maior economia do grupo. A China - tanto o governo central quanto o governo de Xangai - vem dando grande apoio ao NBD. Mas os cinco países fundadores têm o mesmo peso no capital e nas decisões. Cada um dos cinco tem $20 \%$ do capital e do poder de voto. Ninguém tem poder de veto sobre decisão alguma.

Todas as decisões no NBD são tomadas por maioria simples ou maioria qualificada - não se requer unanimidade para nenhuma decisão, pois isto equivaleria a dar poder de veto a cada um dos membros. A experiência da União Europeia, diga-se de passagem, mostra de forma clara o efeito paralisante da exigência de unanimidade para a tomada de decisões. No FMI e no Banco Mundial, os europeus (atuando em bloco) e os Estados Unidos têm poder de veto sobre decisões cruciais.

Estudos Avançados - Em que medida as políticas ou geopolíticas do banco influenciarão as políticas e estratégias nacionais de cada país tomador?

Não é esse o propósito. Primeiro, o NBD não tem "geopolíticas", apenas políticas operacionais e de outros tipos, como qualquer banco de desenvolvimento. É um banco que se limitará a financiar projetos e mobilizar recursos para as áreas de infraestrutura e desenvolvimento sustentável. Não temos a pretensão de influir sobre as políticas e estratégias nacionais dos países tomadores. Respeitaremos a soberania dos países e analisaremos os projetos dentro do marco das políticas e legislações nacionais. $\mathrm{O}$ banco não vai estabelecer condicionalidades nem vincular a aprovação de projetos e desembolsos a mudanças nas políticas e estratégias dos países.

Estudos Avançados - Como está estruturada a governança do novo banco e como esse formato impacta ou implica relações de poder e controle sobre sua estratégia entre os cinco membros fundadores?

Os países se fazem representar no Conselho de Governadores e na Diretoria. A autoridade política máxima é o Conselho de Governadores, integrado pelos ministros de Finanças dos cinco países. A Diretoria do Banco, que é não residente, é integrada, em geral, por secretários de assuntos internacionais dos Ministérios de Finanças ou funcionários de nível equivalente. A Diretoria aprova todas as políticas e projetos do NBD.

A administração do Banco, residente em Xangai, é composta pelo presidente e por quatro vice-Presidentes. Os integrantes da Administração devem lealdade exclusiva ao banco e não representam países. O presidente tem mandato de cinco anos; os vices, mandatos de seis anos. Em Fortaleza, estabeleceu-se uma rotação, com a Índia designando o primeiro presidente. O Brasil indicará o segundo.

Estudos Avançados - Qual a diferença entre o NBD e o banco de fomento asiático sob o comando da China Asian Infrastructure Investment Bank (AIIB)? 
A primeira diferença é justamente esta: o AIIB é controlado pela China, que tem a maior participação no capital e poder de veto sobre decisões importantes. No NBD, há equilíbrio entre os cinco sócios fundadores. Outra diferença é que o AIIB tem foco na Ásia, embora possa atuar também em outras regiões. O NBD tem escopo global.

Além disso, o AIIB escolheu atrair um grande número de membros, inclusive importantes países desenvolvidos como a Alemanha, a França e o Reino Unido, mesmo antes de concluir a negociação do seu Convênio Constitutivo. O NBD decidiu começar só com os cinco sócios fundadores e deixar a ampliação do número de membros para depois que estivessem consolidados o arcabouço de políticas e a estratégia do banco. Só recentemente, um ano depois do início do NBD, é que começamos a contatar potenciais novos membros. Isso nos deu mais liberdade para inovar na definição das políticas e da estratégia.

A presença de países desenvolvidos na fase inicial é uma faca de dois gumes. Ajuda, por um lado, a dar prestígio à instituição. Por outro, tende a dificultar a definição de políticas e orientações diferentes daquelas seguidas pelos principais bancos multilaterais já existentes, como o Banco Mundial e outros, que são controlados pelos países desenvolvidos.

Estudos Avançados - Qual será a moeda central utilizada? Qual será o peso da moeda chinesa na estrutura dos empréstimos e funding do banco? Há uma estratégia de minimizar o papel do dólar como moeda central?

A unidade de conta é o dólar dos Estados Unidos. O Convênio Constitutivo define o capital autorizado (US\$ 100 bilhões), o capital subscrito (US\$ 50 bilhões) e o capital integralizado ou pago (US\$ 10 bilhões) em dólares. Não há uma estratégia deliberada de minimizar o dólar, mas o NBD pretende captar e emprestar não só em dólar, mas também nas moedas dos países membros. Por exemplo, o nosso primeiro bônus foi emitido em yuan, na China. Trata-se, aliás, de um bônus verde que será destinado exclusivamente a energia renovável e outros projetos de cunho ambiental.

Estudos Avançados - Como o NBD pretende trabalhar com os bancos de desenvolvimento locais, como o BNDES?

Os bancos nacionais de desenvolvimento dos Brics são parceiros importantes do NBD. O nosso primeiro acordo de cooperação foi assinado com o BNDES, em 2015. A primeira operação do NBD com o Brasil é com o BNDES, uma linha de crédito de US\$ 300 milhões vinculada a projetos na área de energia renovável, eólica e solar notadamente. O NBD pretende aprender com a experiência dos bancos nacionais de desenvolvimento e valer-se do seu conhecimento dos mercados nacionais. Estamos recebendo também funcionários do BNDES e de outros bancos nacionais de desenvolvimento. 
Estudos Avançados - Quais os tipos de projetos em que o NBD pretende atuar no curto prazo? E no longo prazo, que espaço em termos de projetos pretende ocupar?

Os cinco primeiros projetos aprovados, um em cada país membro, foram todos na área de energia renovável. Eles aumentarão a capacidade de geração de energia renovável em cada um dos países, contribuindo para a redução na emissão de gases de efeito estufa. O total aprovado foi de US\$ 911 milhões; a maior operação foi o mencionado empréstimo ao BNDES. Na China, por exemplo, foi aprovado um empréstimo equivalente a US\$ 81 milhões de doláres, denominado em yuan, que financiará a geração de $100 \mathrm{MW}$ de energia solar, com a implantação de painéis no topo de galpões e edifícios em uma das zonas industriais de Xangai.

Embora neste momento as operações tenham se concentrado em empréstimos com garantia soberana ou por meio de bancos nacionais de desenvolvimento e outros intermediários financeiros, à medida que desenvolvermos nossa capacidade institucional e técnica, o NBD deve explorar diversas modalidades de operação. O Convênio Constitutivo do banco prevê a possibilidade de empréstimos para o setor privado, bem como o uso de garantias e o investimento por meio de participação direta. $\mathrm{O}$ NBD deverá também conceder financiamento a Estados e municípios que apresentem projetos na área de infraestrutura sustentável.

Recebido em 10.08.2016 e aceito em 24.08.2016.

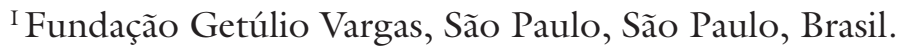

